Amy Waldman, MD*

Jayne Ness, MD*

Daniela Pohl, MD, PhD

Isabella Laura Simone, MD

Banu Anlar, MD

Maria Pia Amato, MD

Angelo Ghezzi, MD

Correspondence to

Dr. Waldman:

waldman@email.chop.edu
Supplemental data at Neurology.org

\section{Pediatric multiple sclerosis}

\author{
Clinical features and outcome
}

\section{ABSTRACT}

Multiple sclerosis (MS) in children manifests with a relapsing-remitting MS (RRMS) disease course. Acute relapses consist of new neurologic deficits persisting greater than 24 hours, in the absence of intercurrent illness, and occur with a higher frequency early in the disease as compared to adult-onset RRMS. Most pediatric patients with MS recover well from these early relapses, and cumulative physical disability is rare in the first 10 years of disease. Brainstem attacks, poor recovery from a single attack, and a higher frequency of attacks portend a greater likelihood of future disability. Although prospective pediatric-onset MS cohorts have been established in recent years, there remains very limited prospective data detailing the longer-term clinical outcome of pediatric-onset MS into adulthood. Whether the advent of MS therapies, and the largely off-label access to such therapies in pediatric MS, has improved prognosis is unknown. MS onset during the key formative academic years, concurrent with active cognitive maturation, is an important determinant of long-term outcome, and is discussed in detail in another article in this supplement. Finally, increasing recognition of pediatric MS worldwide, recent launch of phase III trials for new agents in the pediatric MS population, and the clear imperative to more fully appreciate health-related quality of life in pediatric MS through adulthood highlight the need for standardized, validated, and robust outcome measures. Neurology ${ }^{\circledR 2016 ; 87 ~(S u p p l ~ 2): S 74-S 81 ~}$

\section{GLOSSARY}

ADS $=$ acquired demyelinating syndrome; $\mathbf{A R R}=$ annualized relapse rate; BAEP $=$ brainstem auditory evoked potentials; CIS = clinically isolated syndrome; EDMUS = European Database for MS; EDSS = Expanded Disability Status Scale; FSS = functional system score; IPMSSG = International Pediatric Multiple Sclerosis Study Group; MEP = motor evoked potential; MS = multiple sclerosis; MSFC = Multiple Sclerosis Functional Composite; OCT = optical coherence tomography; $\mathbf{O N}=$ optic neuritis; PASAT $=$ paced auditory serial addition task; PedsQL $=$ Pediatric Quality of Life Inventory; RNFL $=$ retinal nerve fiber layer; SDMT = Symbol Digit Modalities Test; $\mathbf{S P M S ~ = ~ s e c o n d a r y ~ p r o g r e s s i v e ~ m u l t i p l e ~ s c l e r o s i s ; ~} \mathbf{S S E P}=$ somatosensory evoked potentials; VEP $=$ visual evoked potentials.

The International Pediatric Multiple Sclerosis Study Group (IPMSSG) proposed a working definition for the diagnosis of multiple sclerosis (MS) in the pediatric age group ${ }^{1,2}$ that incorporates the $2010 \mathrm{McDonald}$ criteria for $\mathrm{MS},{ }^{3}$ and minor revisions to this definition are detailed in "Consensus definitions for pediatric MS and other demyelinating disorders in childhood" (p. S8). Reported incidence of pediatric MS is variable, possibly secondary to methodologic and regional differences (table 1). Incidence ranges from 0.07 to 2.9 per 100,000 children., ${ }^{4, \mathrm{e}-\mathrm{e} 18}$

Early accurate diagnosis of MS in childhood is important for the overall management of physical, cognitive, and quality of life issues. MS remains a diagnosis based on clinical findings, supported by MRI, CSF, and other laboratory results, and is predicated on the exclusion of other disorders. "Differential diagnosis and evaluation in pediatric inflammatory demyelinating disorders" (p. S28) delineates disorders to consider in the differential of pediatric MS and describes key clinical features that should prompt consideration of disorders other than MS. MRI features of disorders that may mimic MS are illustrated in "MRI in the evaluation of pediatric multiple sclerosis" (p. S88).

\footnotetext{
*These authors contributed equally to this work as co-first authors.

From the Division of Neurology, Department of Pediatrics (A.W.), Children's Hospital of Philadelphia and Perelman School of Medicine at the University of Pennsylvania; Department of Pediatrics (J.N.), University of Alabama at Birmingham and Children's of Alabama; Department of Neurology (D.P.), Children's Hospital of Eastern Ontario, University of Ottawa, Canada; Department of Basic Medical Sciences, Neurosciences and Sense Organs (I.L.S.), University of Bari, Italy; Department of Pediatric Neurology (B.A.), Hacettepe University, Ankara, Turkey; Department NEUROFARBA, Section Neurosciences (M.P.A.), University of Florence; and Divisione di Neurologia 2-Centro Studi Sclerosi Multipla (A.G.), Ospedale di Gallarate, Italy.

Go to Neurology.org for full disclosures. Funding information and disclosures deemed relevant by the authors, if any, are provided at the end of the article.
} 


\begin{tabular}{|c|c|c|c|c|c|}
\hline Table 1 & \multicolumn{5}{|c|}{ Incidence or prevalence estimates of pediatric multiple sclerosis (MS) } \\
\hline $\begin{array}{l}\text { Year of } \\
\text { publication } \\
\text { and ref. }\end{array}$ & Study design, population & Years & Study criteria & Pediatric MS, n & $\begin{array}{l}\text { Incidence of pediatric MS per } \\
100,000 \text { children }(95 \% \mathrm{Cl})\end{array}$ \\
\hline $2007^{e^{1}}$ & $\begin{array}{l}\text { Prospective national survey, } \\
\text { Germany }\end{array}$ & $1997-1999$ & ADS onset $<16 y$ & 132 & 0.3; Age <10: 0.1 \\
\hline $2009^{4}$ & $\begin{array}{l}\text { Prospective national survey, } \\
\text { Canada }\end{array}$ & $2004-2007$ & ADS onset $<18 y$ & $\begin{array}{l}\text { NS (219 ADS, includes } 49 \text { TM, } \\
51 \text { ON) }\end{array}$ & $\begin{array}{l}\text { NS (all ADS 0.9; ADEM, TM, } \\
\text { ON each 0.2) }\end{array}$ \\
\hline $2010^{\mathrm{e} 2}$ & $\begin{array}{l}\text { Retrospective cohort, } \\
\text { Fukuoka, Japan }\end{array}$ & $1998-2003$ & MS onset $<15$ y & 8 & NS; prevalence 1.3 \\
\hline $2011^{\mathrm{e}}$ & $\begin{array}{l}\text { Retrospective HMO-insured } \\
\text { cohort, Southern California }\end{array}$ & $2004-2009$ & ADS onset $<18 y$ & 25 & $0.51(0.33-0.75)$ \\
\hline $2012^{\mathrm{e} 4}$ & Retrospective cohort, Israel & $1995-2009$ & MS onset $<18$ y & $84 \mathrm{MS}$ (age <12: 10) & 2.7; Age <12: $0.1(0.0-0.31)$ \\
\hline $2012^{e 5}$ & $\begin{array}{l}\text { Retrospective cohort, } \\
\text { Washington, DC }\end{array}$ & $2004-2009$ & $\begin{array}{l}\text { Acquired white matter } \\
\text { disorders }<18 \text { y }\end{array}$ & 27 & 0.41 \\
\hline $2014^{e^{7}}$ & $\begin{array}{l}\text { Prospective national survey, } \\
\text { Germany }\end{array}$ & $2009-2011$ & $\begin{array}{l}\text { MS onset }<16 \text { y with } \\
\text { correction for } \\
\text { underreporting }\end{array}$ & $\begin{array}{l}\text { 126; Corrected estimate } 227 \\
(12<\text { age } 11 \text {; estimated } 22)\end{array}$ & $\begin{array}{l}0.64 \text { (0.56-0.73, Corrected); age } \\
<11: 0.09(0.06-0.14)\end{array}$ \\
\hline $2014^{\mathrm{e}}$ & $\begin{array}{l}\text { Prospective cross-sectional } \\
\text { cohort, Shiraz, Iran }\end{array}$ & $2010-2012$ & ADS onset $1-18$ y & 32 & 0.07 (Estimated) \\
\hline $2015^{e 9}$ & Retrospective cohort, Kuwait & $1994-2013$ & MS onset $<18$ y & 122 & $\begin{array}{l}\text { Incidence: 1994: 0.3, 2013: 2.9; } \\
\text { prevalence, 1994: 1.3, 2013: } 6.0\end{array}$ \\
\hline $2015^{e 10}$ & $\begin{array}{l}\text { Retrospective cohort, } \\
\text { Northern Sardinia, Italy }\end{array}$ & 2001-2012 & MS onset $<18$ y & 21 & Incidence: 2.85 ; prevalence: 26.92 \\
\hline
\end{tabular}

Abbreviations: $\mathrm{ADEM}=$ acute disseminated encephalomyelitis; $\mathrm{ADS}=$ acquired demyelinating syndrome; $\mathrm{Cl}=$ confidence interval; $\mathrm{HMO}=$ health maintenance organization; $\mathrm{NS}=$ not stated; $\mathrm{ON}$ = optic neuritis; $\mathrm{TM}=$ transverse myelitis.

The present article focuses on the clinical features of MS in children and adolescents, summarizes the available literature on shortand longer-term neurologic outcome, and describes outcome measures that may serve as valuable metrics to quantify MS in the pediatric age group.

DEMOGRAPHIC FEATURES MS onset is most frequent during adolescence but many series of pediatric MS report patients with symptom onset below age 10 and sometimes as low as 2 years of age. MS onset before 10-12 years of age is rare, accounting for $<1 \%$ of all MS cases in nearly all populationbased series (table 2). ${ }^{5-8, \mathrm{el}-\mathrm{el} 18}$

Prospective pediatric MS series, published in English since 2007 when the IPMSSG consensus definitions ${ }^{1}$ were first published, are summarized in table 3. The studies include $>1,100$ patients from Wales, North America, Iran, France, and Belgium as well as 2 German national surveillance studies of pediatric MS obtained 12 years apart. $5,6,9,10, \mathrm{el}-\mathrm{e} 18$

Notable is the female preponderance, with an overall ratio of up to 4.5:1, and a mean age at onset between 12 and 16 years. The female:male ratio is lower in patients with younger onset MS $(<10-12$ years of age) with an even distribution or male predominance in some studies, although other studies still report a higher number of female patients in the younger age group., ${ }^{5,11, \mathrm{e}-\mathrm{e} 18}$ The potential for hormonal state to explain the marked rise in the proportion of female patients after age 12 years is currently being explored, although analyses are challenged by the need to measure circulating hormones at defined timepoints of the day. The role of hormonal influences on MS onset and disease course across the age span is reviewed elsewhere. ${ }^{12}$ In a prospective longitudinal study of Canadian children presenting for an acquired demyelinating syndrome (ADS), girls with later age at menses were less likely to be diagnosed with MS even after correcting for older age at ADS onset. ${ }^{13}$ In a US cohort of female pediatric patients with MS followed before, during, and after menarche, individual relapse rates were higher during the epoch of menarche (defined as 6 months before and after menarche) compared to relapse rates postmenarche. ${ }^{14}$ Younger girls (at least 6 months prior to menarche) had a lower relapse rate compared to girls within 6 months of menarche in unadjusted models; however, there was no difference after adjusting for exposure to disease-modifying therapy.

CLINICAL FEATURES OF THE INITIAL DEMYELINATING EVENT An ADS may be the first attack of MS, may occur as a monophasic illness, or can be the initial manifestation of other CNS 
Table 2 Percentage of pediatric multiple sclerosis (MS) among all patients with MS in single-center or single-country cohorts

\begin{tabular}{|c|c|c|c|c|c|c|}
\hline $\begin{array}{l}\text { Year of publication } \\
\text { and ref. }\end{array}$ & Study type, population & Pediatric MS criteria & Pediatric MS, n & $\begin{array}{l}\text { Adult-onset MS } \\
\text { (AOMS), n }\end{array}$ & $\begin{array}{l}\% \text { Pediatric } \\
\text { MS }\end{array}$ & $\begin{array}{l}\% \text { Onset } \\
<10 y\end{array}$ \\
\hline $1997^{e 11}$ & Retrospective cohort, Italy & Onset $<16$ y & 149 & 3,226 & 4.4 & NS \\
\hline $2002^{8}$ & $\begin{array}{l}\text { Retrospective cohort, Vancouver, } \\
\text { Canada }\end{array}$ & Onset $<16$ y & $129(23<10 y)$ & $\begin{array}{l}\text { 3,583 } \\
\text { (Extrapolated) }\end{array}$ & 3.5 & 0.64 \\
\hline $2002^{e 12}$ & Retrospective cohort, Italy & Onset $<16$ y & $83(13<10 y)$ & 793 & 9.5 & 1.6 \\
\hline $2006^{13}$ & Retrospective cohort, Belgium & Onset $<17$ y & 146 & 2,154 & 6.3 & NS \\
\hline $2009^{e 14}$ & Prospective cohort, Padova, Italy & Onset $<18$ y & 48 & $\begin{array}{l}671 \text { AOMS in } \\
2003\end{array}$ & $\begin{array}{l}6.7 \\
\text { Estimate }\end{array}$ & NS \\
\hline $2009^{7}$ & Retrospective cohort, Detroit, MI & Onset $<18$ y & 46 & 2,790 & 1.6 & NS \\
\hline $2012^{\mathrm{e} 4}$ & Retrospective cohort, Israel & Onset $<18$ y & $84(10<12$ y) & 1,045 & 7.4 & 0.95 \\
\hline $2012^{e 15}$ & Retrospective survey, Brazil & Onset $<18$ y & $125(19<11$ y) & 2,165 & 5.5 & 0.87 \\
\hline $2012^{22}$ & Retrospective cohort, Iraq & Onset $<18$ y & $77(7<10 y)$ & 1,048 & 6.84 & 0.66 \\
\hline $2013^{10}$ & Prospective cohort, Southeast Wales & Onset $<18$ y & $111(7<10 y)$ & 2,068 & 5.1 & 0.34 \\
\hline
\end{tabular}

Abbreviation: NS = not stated.

demyelinating disorders. In the present article, we focus solely on the presenting features of MS in children.

The initial and highly variable clinical manifestations of pediatric MS have been reported in several studies. Table 3 provides an overview of the clinical presentations described in prospective studies since 2007, and table 4 summarizes differences between pediatric- and adult-onset MS. ${ }^{5,6,9,10, \mathrm{e} 1-\mathrm{e} 18}$ Most children present with symptoms similar to those seen in adult patients with relapsing-remitting MS, including visual loss, paresthesias, weakness, ataxia, diplopia, or urinary symptoms, localizing to the optic pathway, brainstem, cerebellum, or spinal cord, either alone or in combination. The initial attack in pediatric MS often occurs as a monofocal clinical event: the symptoms of the initial attack localize to one area of the CNS in $54 \%-90 \%$ of pediatric cohorts. ${ }^{\text {e1-e18 }}$ Younger children (younger than 10 years) are more likely to manifest with brainstem involvement, $, 511,15$ and may present with polyfocal deficits and encephalopathy. ${ }^{4}$ Distinguishing the first attack of MS from acute disseminated encephalomyelitis (reviewed in "Acute disseminated encephalomyelitis: Updates on an inflammatory CNS syndrome," p. S38) is challenging in these patients, and it is notable that application of the 2010 McDonald criteria for MS diagnosis specifically excludes the ability to diagnose MS at the time of a first attack in patients with an acute disseminated encephalomyelitis phenotype. ${ }^{3}$

In the last decade, several small studies have reported the occurrence of seizures in pediatric patients with MS, with various frequencies (5\%-16\%), sometimes already occurring at disease onset. ${ }^{5,16}$ Seizures are more common in polysymptomatic presentations. Headache, fever, vomiting, lethargy, altered mental status, and seizures together were seen in $7.4 \%$ of 394 children. $^{5}$

DISEASE COURSE Both retrospective and prospectively collected cohorts demonstrate a relapsingremitting disease course in $>98 \%$ of pediatric MS cases. Primary progressive MS is reported to comprise $\sim 15 \%$ of the adult MS population but less than $2 \%$ of pediatric patients with MS in recent series. ${ }^{5}$ Children who have a progressive course from onset of a MS-like illness should undergo extensive assessment for alternative diagnoses, such as mitochondrial, neoplastic, and neurodegenerative disorders. A detailed discussion of differential diagnosis of pediatric MS is found in "Differential diagnosis and evaluation in pediatric inflammatory demyelinating disorders" (p. S28).

RELAPSE RATE Pediatric MS is characterized by frequent relapses in the first few years following onset (defined as the first attack) compared to adult MS. In a prospective study of 21 pediatric- and 110 adult-onset patients with MS, the annualized relapse rate (ARR) after 3 years was 1.1 for the pediatric patients compared to 0.4 in the adult MS group $(p<0.001) .{ }^{17}$ The higher relapse rate in the pediatric-onset group persisted when evaluated over a 6-year period after disease onset in a larger cohort ( 0.8 for 84 patients with pediatric MS vs 0.3 for adult 


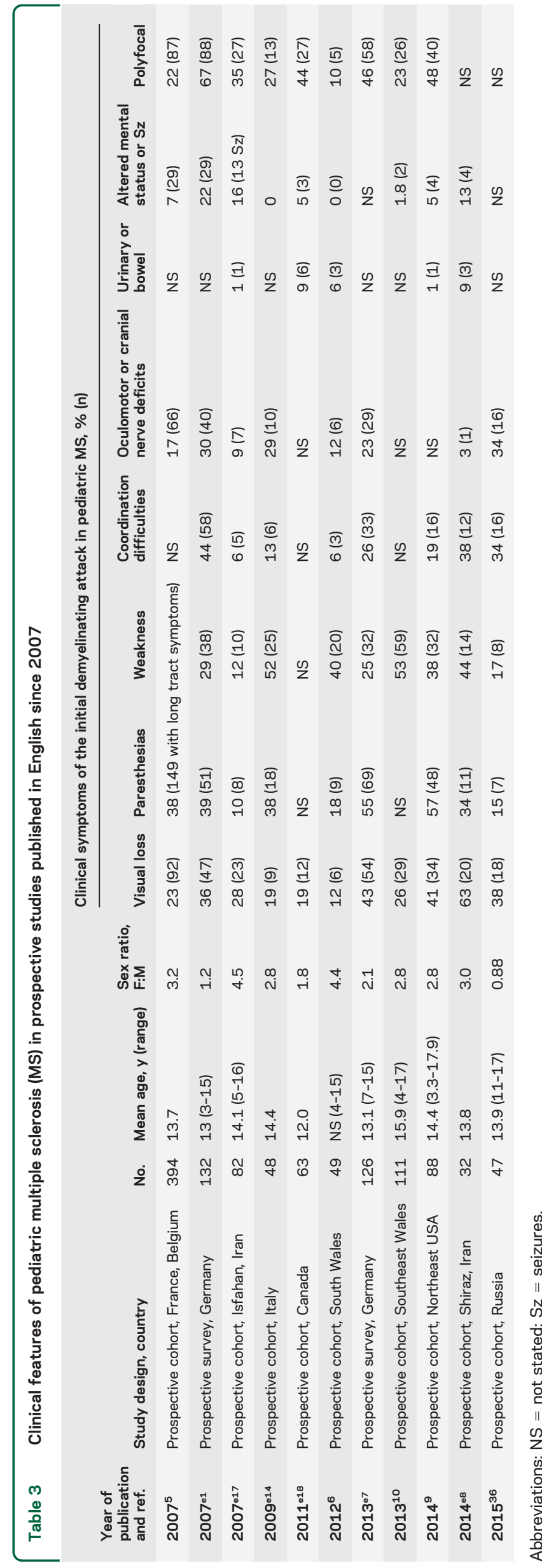

patients with MS, $p<0.001){ }^{9}$ Additionally, there was a shorter interval between the first and second relapse in the 84 pediatric patients with MS compared to 258 adult patients with MS (hazard ratio 1.74, 95\% confidence interval 1.32-2.29), even after diseasemodifying therapy use was taken into account. ${ }^{9}$

RELAPSE SEVERITY AND RECOVERY Compared to adult MS, children and adolescents with MS may experience more severe relapses but also recover more fully. In a retrospective cohort single-center study based in San Francisco, ${ }^{18}$ the following scoring system was used to determine the severity of attacks: mild (defined as a functional system scores [FSS] of $0-1$ in 3 or fewer domains, visual acuity better than 20/40, or Expanded Disability Status Scale [EDSS] 0-1.5), moderate (FSS of 2 in 2 or fewer domains or an FSS of 1 in more than 3 domains, visual acuity 20/40-20/190, or EDSS 22.5), or severe (exceeding the parameters for moderate). Using these criteria, the initial demyelinating attacks in 105 pediatric patients with MS were classified as mild in $16 \%$, moderate in 32\%, and severe in $53 \%$. In comparison, only $17 \%$ of initial attacks were severe in an earlier adult MS cohort from the same center. ${ }^{19}$ Complete recovery (defined as FSS 0 and EDSS 0) was attained in two-thirds of pediatric patients with MS but only $46 \%$ of adults. In contrast, a Boston-based study of pediatric and adult patients with MS with optic neuritis $(\mathrm{ON})$ as their first attack found no difference in ON severity between adult patients with MS ( $\mathrm{n}=$ $253)$ and pediatric patients with MS $(\mathrm{n}=38){ }^{20}$ However, visual recovery 1 year later was better in patients with pediatric MS compared to adults.

In Canadian patients with ADS identified and followed prospectively, all of the 59 children who were confirmed to have MS recovered fully from their first demyelinating event and continued to return to normal neurologic examinations despite 1-2 additional relapses in 50\% over the 4-year follow-up period. ${ }^{21}$ Three additional studies have also shown complete recovery after a first attack of MS. Of 236 pediatric patients with MS from the United Kingdom and Iraq included in these 3 studies, 176 (75\%) recovered fully after the first event. ${ }^{6,10,22}$

African ancestry is often associated with increased MS severity in North American adult patients with MS. Similar observations were made in a Detroit pediatric MS cohort in which patients with an African American heritage ( $\mathrm{n}=24,83 \%$ female) had a higher ARR of 1.8 in 42 months of follow-up compared to white patients with ARR of 1.1 in 38 months of follow-up $(\mathrm{n}=19)$. $^{7}$ The higher ARR was not explained by age at onset or by lack of access to MS therapies. 
Table 4 Summary of the clinical features that distinguish pediatric multiple sclerosis (MS) from adult MS

Category

Sex

Clinical symptoms

Frequency of relapses

Severity of relapses

Clinical recovery after a first event

Disability

Outcome measures

Description

In pediatric MS with onset less than 11 years, the female:male ratio is lower; a greater female preponderance occurs after puberty. A first attack of pediatric MS is typically monofocal. A polyfocal presentation is more common in the younger age group. The symptoms of pediatric MS are similar to adults, although initial attacks affecting the brainstem are more common in pediatric MS.

A higher annualized relapse rate occurs in pediatric MS compared to adult-onset disease.

Relapses are often categorized as severe (by Expanded Disability Status Scale, functional system scores, or visual deficits) in pediatric MS compared to adult MS.

Despite an increase in the severity of neurologic deficits at the time of relapse, most children completely or near-completely recover from their first clinical attack.

Although the time to reach the threshold associated with irreversible neurologic damage may be longer in pediatric MS, significant disability is accrued at a younger age. Once this point is reached, the period associated with progressive decline is similar between pediatric and adult MS.

The extrapolation of outcome measures used in adult randomized clinical trials to pediatric MS is challenged by increasing age and ability as well as brain maturation over childhood and adolescence.

OUTCOME To date, the EDSS score has been utilized to quantify physical outcome in pediatric and adult MS cohorts. The largest pediatric-onset MS outcome data were abstracted from the European Database for MS (EDMUS), which includes adults with MS from France and Belgium. Analysis of outcome was performed for 394 patients with age at MS onset prior to 16 years, enrolled in the study between 1976 and 1997 (and thus diagnosed with MS using Poser criteria ${ }^{23}$ ) and followed through 2003. Nearly $60 \%$ of these pediatric-onset patients with MS had been exposed to one or more medications including interferon- $\beta$, glatiramer acetate, azathioprine, cyclophosphamide, or methotrexate at some point in their disease course. Time to reach an EDSS of 4 (defined as having limited ability but able to walk at least 500 meters without assistance or rest) occurred approximately 20 years after the first attack for pediatric-onset patients with MS, as compared to adult-onset patients with MS, who required only 8 years to reach this outcome. Once an EDSS score of 4 was obtained, subsequent disease progression was similar in pediatric and adult patients with MS, with both groups progressing from EDSS 4 to 7 (inability to walk $>10$ meters without rest) in 12.2 years on average for both pediatric- and adult-onset MS. ${ }^{5}$

Another population-based study in the United Kingdom ${ }^{10}$ of 111 pediatric patients with MS (first attack $<18$ years) revealed similar times to EDSS scores of 4, 6, and 8 as the EDMUS study. Incomplete recovery after a first clinical attack predicted an early median time to reach an EDSS of 4 (13.5 years in those with residual disability compared to 25.4 years in those with complete recovery from the first attack) in the UK cohort, a finding also described in another EDMUS study. ${ }^{24}$

Development of secondary progressive MS (SPMS; defined in the EDMUS database as progressive neurologic impairment, with or without discrete relapses) also took 10 years longer in pediatric MS, occurring at a median of 28.1 years after the first attack of pediatric MS compared to 18.8 years for adult-onset patients, although the median age of the person at SPMS onset was 10 years earlier in pediatric patients with MS (41 years) vs adult MS (52 years). ${ }^{5}$ This study and others ${ }^{8, \mathrm{el}-\mathrm{e} 18}$ demonstrate that a longer disease duration in pediatric MS is required to reach irreversible disability defined using the EDSS or a secondary-progressive disease course; however, outcomes by chronologic age are poorer compared to adult patients with MS.

\section{PROGNOSTIC FACTORS FOR CLINICAL DISEASE} SEVERITY A short interval (less than 1 year) between the first 2 demyelinating episodes ${ }^{24}$ is associated with an increased risk of having a third attack or reaching a disability status scale score $\geq 4$. An incomplete recovery after the first attack ${ }^{18}$ is also an unfavorable prognostic factor associated with a greater risk of having additional attacks with incomplete recovery, thus increasing the risk of cumulative disability over time. Brainstem involvement at onset portends a poor prognosis ${ }^{8}$ with a risk of secondary progressive disease in the future more than 5 times higher than in children whose initial attack affects other brain regions $(p=0.01) .^{25}$

MEASURING CLINICAL DISEASE SEVERITY IN PEDIATRIC MS To date, there are no evaluative tools to quantify global disease severity validated specifically in the pediatric MS population. As discussed, EDSS is a particularly insensitive metric for pediatric MS evaluation, given that the accrual of physical disability in pediatric patients with MS occurs rarely within the first years postonset. Other limitations of the EDSS - specifically that is it a nonlinear, ordinal scale heavily weighted on measures of gait-are well-acknowledged for adult MS studies. ${ }^{26}$ Dynamic measures of physical, visual, and 
cognitive function may be more sensitive to the subtle impairments that characterize pediatric MS.

The Multiple Sclerosis Functional Composite (MSFC) was developed as an outcome tool for adult clinical trials and aims to capture the relevant clinical dimensions in MS (arm, leg, and cognitive function) using quantifiable scales, namely the timed 25-foot walk, 9-hole peg test, and paced auditory serial addition task (PASAT), respectively. ${ }^{27}$ However, the MSFC has not been studied in pediatric MS, and it is unknown whether the scores on these individual scales would differ in children with MS from age- and sex-matched healthy children. Although the 9-hole peg test in children and a children's version of the PASAT (with numbers adding only up to 10) have been performed in healthy children, ${ }^{28,29}$ normative data for the timed 25-foot walk in children and adolescents are lacking and the short distance may not be sensitive enough to distinguish children from healthy controls. A more demanding active task, such as the 6-minute walk, may be required to detect early motor impairment in pediatric patients with MS but would require validation. In addition, longitudinal use of the MSFC in children is further challenged by change in the individual components of these scales that may occur with increasing age and ability.

Identifying tools that are sensitive to detect the subtle disability in pediatric MS and capture change over time are also needed for pediatric therapeutic MS trials. The IPMSSG recommends time to next relapse or ARR be used as primary outcome measures for randomized controlled trials. ${ }^{30}$ Secondary outcome measures could include the EDSS, cognitive tests (such as the Symbol Digit Modalities Test [SDMT]), optical coherence tomography (OCT), and quality of life scales.

The SDMT has been proposed as a screening tool for the detection of cognitive impairment in MS. In pediatric MS ( $\mathrm{n}=31)$ and healthy controls ( $\mathrm{n}=$ 32 ), the $z$ score for the SDMT (comparing the raw score to age- and sex-matched healthy children) correlated with a neuropsychological battery index $z$ score (an average of the $z$ scores for individual tests of general intellect, attention, verbal learning and memory, visuomotor skills, executive function, language, and achievement) $(r=-0.47, p<0.0001){ }^{31}$ The cognitive deficits in pediatric MS are described in greater detail in "Pediatric multiple sclerosis: Cognition and mood" (p. S82).

Vision is frequently affected in MS, and visual outcome measures have been incorporated into adult studies and clinical trials. ${ }^{32}$ The anterior visual pathway has been interrogated in pediatric MS using functional scales (such as low-contrast letter acuity) and structural imaging (with OCT). While decreased lowcontrast letter acuity scores and retinal nerve fiber layer (RNFL) thinning have been demonstrated in pediatric patients with $\mathrm{MS}$ with a history of $\mathrm{ON},{ }^{33}$ there are conflicting data regarding the relationship between deficits in low-contrast visual function and retinal pathology in the eyes of children with MS unaffected by a clinical attack of ON (MS non-ON eyes). ${ }^{34,35}$ One study has shown preserved RNFL in MS non-ON eyes, ${ }^{33}$ suggesting that OCT may capture only local thinning after ON. However, 2 other studies have shown decreased RNFL in pediatric MS non-ON eyes, suggesting that OCT might capture a more global degenerative component of MS. ${ }^{34,35}$ Further validation of OCT as an outcome in pediatric MS is needed.

Another tool used to interrogate the visual pathway is a neurophysiologic test, visual evoked potentials (VEP). VEP, as well as somatosensory evoked potentials (SSEP) and brainstem auditory evoked potentials (BAEP), have been used primarily to identify asymptomatic areas of demyelination. A prospective study of pediatric patients with MS who underwent ophthalmologic evaluation within 2 months of symptom onset identified unilateral ON in 38\% (18 of 47) but P100 latency was prolonged ( $>110$ milliseconds) in 58\% (27 of 47), including 21\% (10) with bilateral involvement. ${ }^{36}$ One-third of patients with abnormal VEP (9 of 27) had a normal eye examination and no history of vision difficulty. These findings are consistent with a larger retrospective study of 85 pediatric patients with MS with VEP, SSEP, and BAEP performed prior to a second clinical attack. ${ }^{37}$ Abnormal evoked potentials (exceeding the mean reference values by $>2.5$ SDs) were found in 19 of 20 patients (95\%) with visual symptoms, 20 of 35 (57\%) patients with sensory symptoms, and 13 of 28 (46\%) patients with brainstem symptoms. Pathologic VEP were measured in 34\% despite no identifiable history of ON and normal visual acuity. Abnormal SSEP and BAEP were found in $9 \%$ and $6 \%$, respectively, of patients without localizable symptoms to these regions. Overall, at least one pathologic evoked potential was found in $82 \%$ of these pediatric patients early in their disease course. While clinical recovery is often complete or close to baseline, these data suggest that abnormalities persist and detectable pathology can be still be measured. The prognostic implications for abnormal evoked potentials in pediatric MS are unknown. In 28 prospectively followed adult patients with MS, combined VEP and motor evoked potentials (MEP, central motor conduction time for abductor digiti minimi and anterior tibial muscles) predicated disability, as measured by the EDSS, after 20 years disease duration, accounting for age and therapy status $(p=0.01) .{ }^{38}$ In fact, VEP and MEP predicted $58 \%$ of the variability in EDSS at year 20, whereas the baseline EDSS or MRI features (number 
of T2 hyperintense or gadolinium-enhancing lesions) did not improve the prediction model. Similar studies have not been performed in pediatric MS.

Two pediatric MS studies have reported lower health-related quality of life, as measured using the Pediatric Quality of Life Inventory (PedsQL) questionnaires, in early pediatric MS (mean or median disease duration $<2$ years for both studies). ${ }^{39,40}$ The greatest reductions in quality of life were detected in the school domain, although physical and psychosocial function were also decreased compared to controls. The summary score for the PedsQL was 16 points lower in a cohort of patients with pediatric MS ( $\mathrm{n}=37)$ and patients with clinically isolated syndrome (CIS, $\mathrm{n}=13$ ) compared to sibling controls $(\mathrm{n}=12, p=0.004) .{ }^{40} \mathrm{~A}$ higher EDSS predicted a lower PedsQL score: a 1-point increase in EDSS was associated with a 4.5-point decrease in total quality of life score $(p=0.014)$. Parents also report decreased health-related quality of life using the PedsQL parent proxy in their children with MS or CIS compared to their healthy children (22-point difference, adjusted for age and sex, $p=0.001$ ).

A common complaint in both pediatric and adult MS is fatigue. In a study of 51 pediatric patients with MS, general fatigue scores using the PedsQL Multidimensional Fatigue Scale were mild (1-2 SDs below age-matched normative data) in $24 \%$ and severe $(\geq 2$ SDs less than normative reference ranges) in $32 \% .{ }^{39}$ The proportion of patients with mild or severe cognitive fatigue (52\%) was double the percentage with mild or severe sleep-related fatigue (26\%), although both are likely to contribute to poor school performance. Parent scores detected a higher percentage of cognitive fatigue $(76 \%)$ in their children compared to general and sleep-related fatigue (63\% for each), and parents scored their children's fatigue as worse (more often $>2$ SDs worse than their peers) compared to their children's self-report. Children should be screened during routine neurologic visits for fatigue since it is a disabling but often treatable symptom.

DISCUSSION The onset of MS during childhood or adolescence follows a relapsing-remitting course with frequent but typically recoverable relapses early in the disease. Nonetheless, due to the early onset of their disease, pediatric patients with MS are at risk to become disabled in early adulthood. Whether current therapies will mitigate this outcome is an area of active research. Creation of robust tools to measure disease severity in pediatric MS is a key imperative. Importantly, collaborative multinational networks are essential to more fully appreciate the spectrum of clinical severity of pediatric MS, and to demonstrate improvement in outcome achieved through therapeutic immunomodulatory and neuroprotective strategies, cognitive and physical rehabilitation, and psychosocial and emotional supports.

\section{AUTHOR CONTRIBUTIONS}

Amy Waldman: drafting and final text of the revised manuscript. Jayne Ness: drafting and final revision of the manuscript. Daniela Pohl: extensive revision and editing of all sections of the manuscript. Isabella L. Simone: drafting and revising the manuscript. Banu Anlar: drafting and final revision of the manuscript. Maria Pia Amato: drafting and revising the manuscript. Angelo Ghezzi: drafting and revising the manuscript.

\section{STUDY FUNDING}

This supplement is made possible by funding from the MS Cure Fund, Danish MS Society, German MS Society, Italian MS Association, MS International Federation, MS Research Foundation (Netherlands), National MS Society (USA) and Swiss MS Society.

\section{DISCLOSURE}

A. Waldman: Research grants from the NIH, research funding from Biogen Idec, member of the advisory board, and site investigator for a pediatric MS trial sponsored by Novartis Pharmaceuticals Corporation. J. Ness: Site investigator for a pediatric MS trial sponsored by Novartis Pharmaceuticals Corporation. D. Pohl reports no disclosures relevant to the manuscript. I. Simone: Honoraria as speaker and member of advisory board of Genzyme-Sanofi Aventis, Teva, Biogen, and Novartis. B. Anlar: Honoraria for speaking from Biogen-Idec and Merck-Serono. M. Amato: Research grants and honoraria as a speaker and member of advisory boards of Bayer, Biogen, Merck Serono, Novartis, Sanofi Genzyme, Teva, and Almirall. A. Ghezzi: Honoraria for speaking from Biogen-Idec, Merck-Serono, Novartis, Genzyme, Teva, and Allergan; for consultancy from Merck-Serono, Teva, Novartis, and Biogen-Idec; and support for participation to National and International Congresses from Schering, Biogen-Idec, Merck-Serono, Novartis, Genzyme, and Teva. Go to Neurology.org for full disclosures.

Received March 13, 2016. Accepted in final form July 1, 2016.

\section{REFERENCES}

1. Krupp LB, Banwell B, Tenembaum S; International Pediatric MSSG. Consensus definitions proposed for pediatric multiple sclerosis and related disorders. Neurology 2007; 68(16 suppl 2):S7-S12.

2. Krupp LB, Tardieu M, Amato MP, et al. International Pediatric Multiple Sclerosis Study Group criteria for pediatric multiple sclerosis and immune-mediated central nervous system demyelinating disorders: revisions to the 2007 definitions. Mult Scler 2013;19:1261-1267.

3. Polman $\mathrm{CH}$, Reingold SC, Banwell B, et al. Diagnostic criteria for multiple sclerosis: 2010 revisions to the McDonald criteria. Ann Neurol 2011;69:292-302.

4. Banwell B, Kennedy J, Sadovnick D, et al. Incidence of acquired demyelination of the CNS in Canadian children. Neurology 2009;72:232-239.

5. Renoux C, Vukusic S, Mikaeloff Y, et al. Natural history of multiple sclerosis with childhood onset. $\mathrm{N}$ Engl J Med 2007;356:2603-2613.

6. Cossburn MD, Ingram G, Hirst CL, Ben-Shlomo $\mathrm{Y}$, Pickersgill T, Robertson N. Age at onset as a determinant of presenting phenotype and initial relapse recovery in multiple sclerosis. Mult Scler 2011;18:45-54.

7. Boster AL, Endress CF, Hreha SA, Caon C, Perumal JS, Khan OA. Pediatric-onset multiple sclerosis in AfricanAmerican black and European-origin white patients. Pediatr Neurol 2009;40:31-33.

8. Boiko A, Vorobeychik G, Paty D, Devonshire V, Sadovnick D. Early onset multiple sclerosis: a longitudinal study. Neurology 2002;59:1006-1010. 
9. Benson LA, Healy BC, Gorman MP, et al. Elevated relapse rates in pediatric compared to adult MS persist for at least 6 years. Mult Scler Relat Disord 2014;3:186-193.

10. Harding KE, Liang $\mathrm{K}$, Cossburn MD, et al. Long-term outcome of paediatric-onset multiple sclerosis: a populationbased study. J Neurol Neurosurg Psychiatry 2013;84: 141-147.

11. Huppke B, Ellenberger D, Rosewich H, Friede T, Gärtner J, Huppke P. Clinical presentation of pediatric multiple sclerosis before puberty. Eur J Neurol 2014;21:441-446.

12. Bove R, Chitnis T. The role of gender and sex hormones in determining the onset and outcome of multiple sclerosis. Mult Scler 2014;20:520-526.

13. Ahn JJ, O’Mahony J, Moshkova M, et al. Puberty in females enhances the risk of an outcome of multiple sclerosis in children and the development of central nervous system autoimmunity in mice. Mult Scler 2015;21:735-748.

14. Lulu S, Graves J, Waubant E. Menarche increases relapse risk in pediatric multiple sclerosis. Mult Scler 2016:22; 193-200.

15. Ghassemi R, Antel SB, Narayanan S, et al. Lesion distribution in children with clinically isolated syndromes. Ann Neurol 2008;63:401-405.

16. Etemadifar M, Abtahi SH, Tabrizi N. Epileptic seizures in early-onset multiple sclerosis. Arch Iran Med 2012;15: 381-383.

17. Gorman MP, Healy BC, Polgar-Turcsanyi M, Chitnis T. Increased relapse rate in pediatric-onset compared with adult-onset multiple sclerosis. Arch Neurol 2009;66: 54-59.

18. Fay AJ, Mowry EM, Strober J, Waubant E. Relapse severity and recovery in early pediatric multiple sclerosis. Mult Scler 2012;18:1008-1012.

19. Mowry EM, Pesic M, Grimes B, Deen S, Bacchetti P, Waubant E. Demyelinating events in early multiple sclerosis have inherent severity and recovery. Neurology 2009; 72:602-608.

20. Taimur M, Healy BC, Benson LA, et al. Factors associated with recovery from acute optic neuritis in patients with multiple sclerosis. Neurology 2014;82:2173-2179.

21. O’Mahony J, Marrie RA, Laporte A, et al. Recovery from central nervous system acute demyelination in children. Pediatrics 2015;136:e115-e123.

22. Al-Hamadani HA, Abdalla AS, Al-Saffar AJ. The course of early-onset multiple sclerosis in Iraqi children. World J Pediatr 2012;8:47-51.

23. Poser CM, Paty DW, Scheinberg L, et al. New diagnostic criteria for multiple sclerosis: guidelines for research protocols. Ann Neurol 1983;13:227-231.

24. Mikaeloff Y, Caridade G, Assi S, Suissa S, Tardieu M. Prognostic factors for early severity in a childhood multiple sclerosis cohort. Pediatrics 2006;118:1133-1139.
25. Akhtar S, Alroughani R, Ahmed SF, Al-Hashel JY. Prognostic indicators of secondary progression in a paediatriconset multiple sclerosis cohort in Kuwait. Mult Scler 2016;22:1086-1093.

26. Rudick R, Antel J, Confavreux C, et al. Recommendations from the National Multiple Sclerosis Society Clinical Outcomes Assessment Task Force. Ann Neurol 1997;42:379-382.

27. Cutter GR, Baier ML, Rudick RA, et al. Development of a multiple sclerosis functional composite as a clinical trial outcome measure. Brain 1999;122:871-882.

28. Smith YA, Hong E, Presson C. Normative and validation studies of the Nine-Hole Peg Test with children. Percept Mot Skills 2000;90:823-843.

29. Dyche GM, Johnson DA. Development and evaluation of CHIPASAT, an attention test for children: II: test-retest reliability and practice effect for a normal sample. Percept Mot Skills 1991;72:563-572.

30. Chitnis T, Tardieu M, Amato MP, et al. International Pediatric MS Study Group clinical trials summit: meeting report. Neurology 2013;80:1161-1168.

31. Charvet LE, Beekman R, Amadiume N, Belman AL, Krupp LB. The Symbol Digit Modalities Test is an effective cognitive screen in pediatric onset multiple sclerosis (MS). J Neurol Sci 2014;341:79-84.

32. Balcer LJ, Galetta SL, Polman CH, et al. Low-contrast acuity measures visual improvement in phase 3 trial of natalizumab in relapsing MS. J Neurol Sci 2012;318:119-124.

33. Waldman AT, Hiremath G, Avery RA, et al. Monocular and binocular low-contrast visual acuity and optical coherence tomography in pediatric multiple sclerosis. Mult Scler Relat Disord 2014;3:326-334.

34. Yeh EA, Weinstock-Guttman B, Lincoff N, et al. Retinal nerve fiber thickness in inflammatory demyelinating diseases of childhood onset. Mult Scler 2009;15:802-810.

35. Yilmaz U, Gucuyener K, Erin DM, et al. Reduced retinal nerve fiber layer thickness and macular volume in pediatric multiple sclerosis. J Child Neurol 2012;27:1517-1523.

36. Voitenkov V, Skripchenko N, Klimkin A. Visual pathways involvement in clinically isolated syndrome in children. Int J Ophthalmol 2015;8:382-384.

37. Pohl D, Rostasy K, Treiber-Held S, et al. Pediatric multiple sclerosis: detection of clinically silent lesions by multimodal evoked potentials. J Pediatr 2006;149:125-127.

38. Schlaeger R, Schindler C, Grize L, et al. Combined visual and motor evoked potentials predict multiple sclerosis disability after 20 years. Mult Scler 2014;20:1348-1354.

39. MacAllister WS, Christodoulou C, Troxell R, et al. Fatigue and quality of life in pediatric multiple sclerosis. Mult Scler 2009;15:1502-1508.

40. Mowry EM, Julian LJ, Im-Wang S, et al. Health-related quality of life is reduced in pediatric multiple sclerosis. Pediatr Neurol 2010;43:97-102. 


\title{
Neurology
}

\author{
Pediatric multiple sclerosis: Clinical features and outcome \\ Amy Waldman, Jayne Ness, Daniela Pohl, et al. \\ Neurology 2016;87;:S74-S81 \\ DOI 10.1212/WNL.0000000000003028
}

This information is current as of August 29, 2016

\begin{tabular}{|c|c|}
\hline $\begin{array}{l}\text { Updated Information \& } \\
\text { Services }\end{array}$ & $\begin{array}{l}\text { including high resolution figures, can be found at: } \\
\text { http://n.neurology.org/content/87/9_Supplement_2/S74.full }\end{array}$ \\
\hline Supplementary Material & $\begin{array}{l}\text { Supplementary material can be found at: } \\
\text { http://n.neurology.org/content/suppl/2016/08/29/WNL.0000000000003 } \\
\text { 028.DC1 }\end{array}$ \\
\hline References & $\begin{array}{l}\text { This article cites } 39 \text { articles, } 1 \text { of which you can access for free at: } \\
\text { http://n.neurology.org/content/87/9_Supplement_2/S74.full\#ref-list-1 }\end{array}$ \\
\hline Citations & $\begin{array}{l}\text { This article has been cited by } 4 \text { HighWire-hosted articles: } \\
\text { http://n.neurology.org/content/87/9_Supplement_2/S74.full\#\#otherartic } \\
\text { les }\end{array}$ \\
\hline Subspecialty Collections & $\begin{array}{l}\text { This article, along with others on similar topics, appears in the } \\
\text { following collection(s): } \\
\text { All Pediatric } \\
\text { http://n.neurology.org/cgi/collection/all_pediatric } \\
\text { Multiple sclerosis } \\
\text { http://n.neurology.org/cgi/collection/multiple_sclerosis }\end{array}$ \\
\hline Permissions \& Licensing & $\begin{array}{l}\text { Information about reproducing this article in parts (figures,tables) or in } \\
\text { its entirety can be found online at: } \\
\text { http://www.neurology.org/about/about_the_journal\#permissions }\end{array}$ \\
\hline Reprints & $\begin{array}{l}\text { Information about ordering reprints can be found online: } \\
\text { http://n.neurology.org/subscribers/advertise }\end{array}$ \\
\hline
\end{tabular}

Neurology ${ }^{\circledR}$ is the official journal of the American Academy of Neurology. Published continuously since 1951, it is now a weekly with 48 issues per year. Copyright @ 2016 American Academy of Neurology. All rights reserved. Print ISSN: 0028-3878. Online ISSN: 1526-632X.

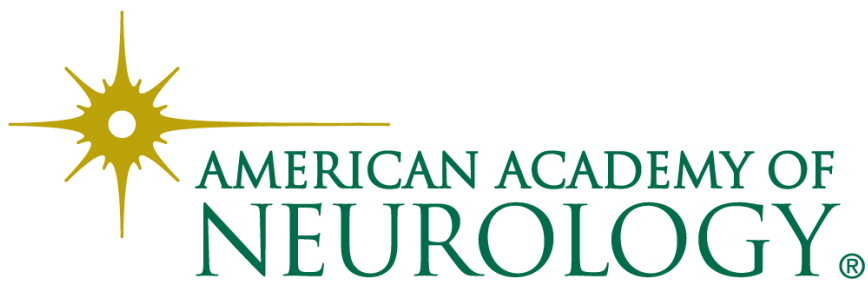

